\title{
Exploring imaging features of molecular subtypes of large cell neuroendocrine carcinoma (LCNEC)
}

Citation for published version (APA):

Hermans, B. C. M., Sanduleanu, S., Derks, J. L., Woodruff, H., Hillen, L. M., Casale, R., Hoesein, F. M., de Jong, E., ten Berge, D. M. H. J., Speel, E. J. M., Lambin, P., Gietema, H. A., \& Dingemans, A-M. C. (2020). Exploring imaging features of molecular subtypes of large cell neuroendocrine carcinoma (LCNEC). Lung Cancer, 148, 94-99. https://doi.org/10.1016/j.lungcan.2020.08.006

Document status and date:

Published: 01/10/2020

DOI:

10.1016/j.lungcan.2020.08.006

Document Version:

Publisher's PDF, also known as Version of record

Document license:

Taverne

Please check the document version of this publication:

- A submitted manuscript is the version of the article upon submission and before peer-review. There can be important differences between the submitted version and the official published version of record.

People interested in the research are advised to contact the author for the final version of the publication, or visit the DOI to the publisher's website.

- The final author version and the galley proof are versions of the publication after peer review.

- The final published version features the final layout of the paper including the volume, issue and page numbers.

Link to publication

\footnotetext{
General rights Owners
rights.

- You may freely distribute the URL identifying the publication in the public portal. please follow below link for the End User Agreement:

www.umlib.nl/taverne-license

Take down policy

If you believe that this document breaches copyright please contact us at:

repository@maastrichtuniversity.nl

providing details and we will investigate your claim.
}

Copyright and moral rights for the publications made accessible in the public portal are retained by the authors and/or other copyright owners and it is a condition of accessing publications that users recognise and abide by the legal requirements associated with these

- Users may download and print one copy of any publication from the public portal for the purpose of private study or research.

- You may not further distribute the material or use it for any profit-making activity or commercial gain

If the publication is distributed under the terms of Article $25 \mathrm{fa}$ of the Dutch Copyright Act, indicated by the "Taverne" license above, 


\title{
Exploring imaging features of molecular subtypes of large cell neuroendocrine carcinoma (LCNEC)
}

\author{
B.C.M. Hermans ${ }^{\mathrm{a}, \mathrm{b}}$, S. Sanduleanu ${ }^{\mathrm{b}, \mathrm{d}}$, J.L. Derks ${ }^{\mathrm{a}, \mathrm{b}}$, H. Woodruff ${ }^{\mathrm{b}, \mathrm{c}, \mathrm{d}}$, L.M. Hillen ${ }^{\mathrm{b}, \mathrm{e}}$, \\ R. Casale ${ }^{\text {b, d }}$, F. Mohamed Hoesein ${ }^{f}$, E. de Jong ${ }^{\text {b, }}$, D.M.H.J. ten Berge ${ }^{\text {g,h }}{ }^{\text {, E.J.M. Speel }}{ }^{\text {b,e }}$, \\ P. Lambin ${ }^{\mathrm{b}, \mathrm{c}, \mathrm{d}}$, H.A. Gietema ${ }^{\mathrm{b}, \mathrm{c}, 1}$, A-M.C. Dingemans ${ }^{\mathrm{a}, \mathrm{b}, \mathrm{h}, 1, *}$ \\ ${ }^{a}$ Department of Pulmonary Diseases, Maastricht University Medical Centre+, P.O. Box 5800, 6202 AZ Maastricht, The Netherlands \\ ${ }^{\mathrm{b}}$ GROW - School for Oncology \& Developmental Biology, Maastricht University, P.O. Box 616, 6200 MD Maastricht, The Netherlands \\ ${ }^{\mathrm{c}}$ Department of Radiology and Nuclear Medicine, Maastricht University Medical Centre+, P.O. Box 5800, 6202 AZ Maastricht, the Netherlands \\ ${ }^{\mathrm{d}}$ The D-Lab, Department of Precision Medicine, Maastricht University, P.O. Box 616, 6200 MD Maastricht, The Netherlands \\ e Department of Pathology, Maastricht University Medical Centre+, P.O. Box 5800, 6202 AZ Maastricht, the Netherlands \\ ${ }^{\mathrm{f}}$ Department of Radiology, University Medical Centre Utrecht, P.O. Box 85500, 3508 GA Utrecht, the Netherlands \\ ${ }^{g}$ Department of Radiology, Erasmus Medical Centre, P.O. Box 2040, 3000 CA Rotterdam, the Netherlands \\ ${ }^{\mathrm{h}}$ Department of Pulmonology, Erasmus Medical Centre, P.O. Box 2040, 3000 CA Rotterdam, the Netherlands
}

\section{A R T I C L E I N F O}

\section{Keywords:}

LCNEC

large cell neuroendocrine carcinoma

radiomics

semantic features

radiological features

\begin{abstract}
A B S T R A C T
Objectives: Radiological characteristics and radiomics signatures can aid in differentiation between small cell lung carcinoma (SCLC) and non-small cell lung carcinoma (NSCLC). We investigated whether molecular subtypes of large cell neuroendocrine carcinoma (LCNEC), i.e. SCLC-like (with pRb loss) vs. NSCLC-like (with pRb expression), can be distinguished by imaging based on (1) imaging interpretation, (2) semantic features, and/or (3) a radiomics signature, designed to differentiate between SCLC and NSCLC.

Materials and Methods: Pulmonary oncologists and chest radiologists assessed chest CT-scans of 44 LCNEC patients for 'small cell-like' or 'non-small cell-like' appearance. The radiologists also scored semantic features of 50 LCNEC scans. Finally, a radiomics signature was trained on a dataset containing 48 SCLC and 76 NSCLC scans and validated on an external set of 58 SCLC and 40 NSCLC scans. This signature was applied on scans of 28 SCLC-like and 8 NSCLC-like LCNEC patients.

Results: Pulmonary oncologists and radiologists were unable to differentiate between molecular subtypes of LCNEC and no significant differences in semantic features were found. The area under the receiver operating characteristics curve of the radiomics signature in the validation set (SCLC vs. NSCLC) was 0.84 (95\% confidence interval (CI) 0.77-0.92) and 0.58 (95\% CI 0.29-0.86) in the LCNEC dataset (SCLC-like vs. NSCLC-like).

Conclusion: LCNEC appears to have radiological characteristics of both SCLC and NSCLC, irrespective of pRb loss, compatible with the SCLC-like subtype. Imaging interpretation, semantic features and our radiomics signature designed to differentiate between SCLC and NSCLC were unable to separate molecular LCNEC subtypes, which underscores that LCNEC is a unique disease.
\end{abstract}

\section{Introduction}

Large cell neuroendocrine carcinoma (LCNEC) of the lung is a rare tumor type, representing $1-3 \%$ of all types of lung cancer $[1,2]$. The histological diagnosis of LCNEC is complex, and preferably, surgical resected tumor tissue is used [3]. LCNEC can be separated in two main molecular subtypes: the first is SCLC-like (pathological SCLC-like,
pSCLC-like), with co-mutation of RB1 and TP53 and loss of immunohistochemical (IHC) pRb expression and the second is NSCLC-like (pNSCLC-like), with co-mutation of TP53 and STK11/KEAP1/KRAS genes and preserved pRb expression [4-6]. These subtypes might be predictive for chemotherapeutic responses [6,7].

Over the past years efforts have been made to differentiate between the two main lung cancer subtypes, small cell lung carcinoma (SCLC)

\footnotetext{
* Corresponding author at: Department of Pulmonology, Erasmus Medical Centre, P.O. Box 2040, 3000 CA Rotterdam, the Netherlands.

E-mail address: a.dingemans@erasmusmc.nl (A.-M.C. Dingemans).

1 These authors contributed equally to this paper.
} 

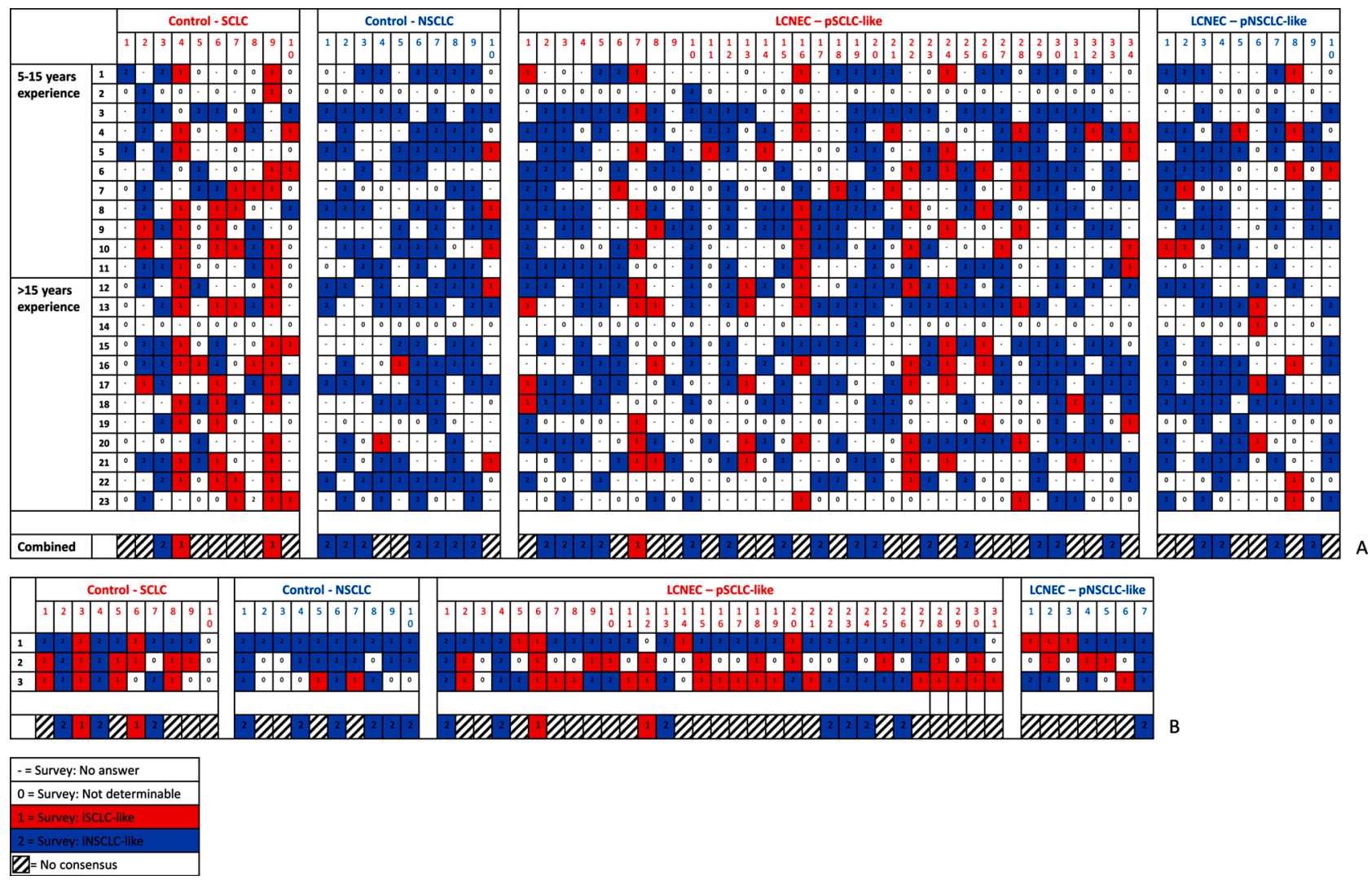

Fig. 1. Individual results of survey among 23 pulmonary oncologists (A) and 3 chest radiologists (B). Each column represents a CT-scan and each row represents a pulmonary oncologist or radiologist. The last row shows the combined score (iSCLC-like: $\geq 50 \%$ scored as small cell-like and none as non-small cell-like, iNSCLC-like: $\geq 50 \%$ scored as non-small cell-like and none as small cell-like, No consensus: all other cases). Abbreviations: SCLC $=$ small cell lung carcinoma, NSCLC $=$ non-small cell lung carcinoma, LCNEC = large cell neuroendocrine carcinoma, pSCLC-like = pathological SCLC-like, pNSCLC-like = pathological NSCLC-like.

and non-small cell lung carcinoma (NSCLC), based on semantic features and radiomics signatures of routinely performed diagnostic chest CTscans $[8,9]$. Classic SCLC is described most commonly as a bulky central mass with major mediastinal lymph node involvement, whereas NSCLC is often located peripherally in the lungs with less extensive nodal involvement [3]. In small case series almost exclusively consisting of stage I-III LCNEC, $0-36 \%$ of the tumors were located centrally [10-15].

In this study we performed an in-depth analysis of CT-scans obtained in daily clinical practice to answer the following questions: 1) Are pulmonary oncologists and chest radiologists able to identify pSCLC-like and pNSCLC-like LCNEC based on their interpretation of radiological images? 2) Are there semantic features associated with molecular LCNEC subtypes and do the LCNEC subtypes resemble SCLC and NSCLC? Radiomics combines quantitative imaging features that can be extracted from standard-of-care medical imaging into so-called signatures [16, 17]. Therefore, we finally investigated 3 ) whether we could classify SCLC and NSCLC based on a radiomics signature and if we could use this signature to identify pSCLC-like and pNSCLC-like LCNEC, under the hypothesis that pSCLC-like LCNEC has comparable radiological characteristics as SCLC and pNSCLC-like LCNEC as NSCLC.

\section{Material and Methods}

\subsection{Patient selection}

Diagnostic pretreatment CT-scans were requested for 158 patients with a confirmed LCNEC diagnosis after pathological review (Supplemental figure A) [6]. IHC pRb (13A10) staining was performed on available formalin fixed paraffin embedded tissue, as described previously [6]. Baseline CT-scans of 127 stage IV SCLC patients and 138 stage IV NSCLC patients were added to the study population (Supplemental figure B) [18].

The study protocol was approved by the medical ethical committee of the Maastricht UMC+ (METC azM/UM 14-4-043) and patient informed consent was waived due to the retrospective and anonymous nature of the study.

\subsection{Imaging interpretation}

A digital survey was developed with representative 2D images of CTscans of LCNEC patients, from whom IHC pRb status was available ( $\mathrm{N}=44)$ to evaluate the imaging interpretation by pulmonary oncologists (Qualtrics XM) (Supplemental figure C). Ten CT-scans of both SCLC and NSCLC patients were randomly included as controls (Supplemental figure A). The survey was distributed among all Dutch pulmonary oncologists, but only answers of clinicians with at least five years' experience were included in the analysis. Participants were asked to score for each CT-scan whether their first impression would be 'small cell', 'nonsmall cell' or 'not determinable based on the radiological image' and a 'combination score' was constructed for each scan (Supplemental methods A and B). Positive predictive values (PPVs) were calculated for imaging SCLC-like (iSCLC-like) and imaging NSCLC-like (iNSCLC-like) survey outcomes and association of molecular subtypes with survey outcome was investigated using the Fisher's exact test. A p-value $<0.05$ was considered significant.

\subsection{Semantic features}

To evaluate semantic features, next to the CT-scans used in the 
Table 1

Semantic features of CT-scans of patients with stage IV large cell neuroendocrine carcinoma $(\mathrm{N}=50)$.

\begin{tabular}{|c|c|}
\hline & $\begin{array}{l}\text { LCNEC } \\
\mathrm{N}(\%)\end{array}$ \\
\hline Total number of patients & 50 \\
\hline \multicolumn{2}{|l|}{ Tumor location } \\
\hline Central & $9(18)$ \\
\hline Peripheral & $20(40)$ \\
\hline ND & $4(8)$ \\
\hline NC & $17(34)$ \\
\hline \multicolumn{2}{|l|}{ Involved lung lobe } \\
\hline LLL & $4(8)$ \\
\hline LUL & $22(44)$ \\
\hline RLL & $5(10)$ \\
\hline RML & $0(0)$ \\
\hline RUL & $14(28)$ \\
\hline ND & $4(8)$ \\
\hline NC & $1(2)$ \\
\hline \multicolumn{2}{|l|}{ Tumor size } \\
\hline$<3 \mathrm{~cm}$ & $10(20)$ \\
\hline $3-7 \mathrm{~cm}$ & $20(40)$ \\
\hline$>7 \mathrm{~cm}$ & $13(26)$ \\
\hline ND & $6(12)$ \\
\hline NC & $1(2)$ \\
\hline \multicolumn{2}{|l|}{$\mathrm{T}$} \\
\hline T0 & $7(14)$ \\
\hline $\mathrm{T} 1$ & $6(12)$ \\
\hline $\mathrm{T} 2$ & $10(20)$ \\
\hline T3 & $19(38)$ \\
\hline $\mathrm{T} 4$ & $0(0)$ \\
\hline ND & $3(6)$ \\
\hline NC & $5(10)$ \\
\hline \multicolumn{2}{|l|}{$\mathrm{N}$} \\
\hline NO & $4(8)$ \\
\hline N1 & $2(4)$ \\
\hline $\mathrm{N} 2$ & $17(34)$ \\
\hline N3 & $24(48)$ \\
\hline ND & $1(2)$ \\
\hline $\mathrm{NC}$ & $2(4)$ \\
\hline \multicolumn{2}{|l|}{ Liver metastases } \\
\hline No & $26(52)$ \\
\hline Limited & $5(10)$ \\
\hline Diffuse & $9(18)$ \\
\hline ND & $9(18)$ \\
\hline NC & $1(2)$ \\
\hline \multicolumn{2}{|l|}{ Aspect tumor } \\
\hline Homogeneous & $16(32)$ \\
\hline Heterogeneous & $29(58)$ \\
\hline ND & $2(4)$ \\
\hline NC & $3(6)$ \\
\hline \multicolumn{2}{|l|}{ Tumor border* } \\
\hline Smooth & $5(10)$ \\
\hline Lobulated & $23(46)$ \\
\hline Spiculated & $26(52)$ \\
\hline \multicolumn{2}{|l|}{ Internal characteristics* } \\
\hline Calcification & $6(12)$ \\
\hline Necrosis & $10(20)$ \\
\hline Air bronchogram & $10(20)$ \\
\hline Cavitation & $1(2)$ \\
\hline Pleural invasion & $15(30)$ \\
\hline Notching & $0(0)$ \\
\hline \multicolumn{2}{|l|}{ External characteristics* } \\
\hline Groundglass & $12(24)$ \\
\hline Bubble lucencies & $0(0)$ \\
\hline Open bronchus sign & $0(0)$ \\
\hline Pleural tag & $7(14)$ \\
\hline Distal mucus plug & $1(2)$ \\
\hline Distal atelectasis & $6(12)$ \\
\hline Pleural fluid & $3(6)$ \\
\hline Satellite lesions & $18(36)$ \\
\hline Emphysema & $24(48)$ \\
\hline
\end{tabular}

Abbreviations: $\mathrm{LCNEC}=$ large cell neuroendocrine carcinoma, ND $=$ Not determinable (could not be determined by $\geq 2 / 3$ radiologists), $\mathrm{NC}=$ No consensus (no majority $(\geq 2 / 3)$ for one answer ( $3 / 3$ for tumor location)), LLL = left lower lobe, $\mathrm{LUL}=$ left upper lobe, $\mathrm{RLL}=$ right lower lobe, $\mathrm{RML}=$ right middle lobe, RUL $=$ right upper lobe

* Multiple answers possible for each scan. survey, additional scans of LCNEC patients with unknown IHC pRb status were included. Patients with missing slices of their CT-scan and those without a clear intrathoracic tumor were excluded (Supplemental figure A). Three experienced and dedicated chest radiologists (RC, FMH, HG) read the scans for semantic features (LCNEC $N=50$, SCLC $N=10$, NSCLC $N=10$ ) and a 'combination score' was constructed for each feature (Supplemental methods B, Supplemental figure D). Association of semantic features with pathological diagnosis was tested with the Fisher's exact test for cases with known IHC pRb status (LCNEC N $=38$ ). Furthermore, the radiologists were asked to interpret the CT-scans in analogy to the pulmonary oncologists.

\subsection{Radiomics signature}

For evaluation of quantitative imaging features, additional scans from SCLC and NSCLC patients were added to the LCNEC and control scans used in the previous parts of this study (Supplemental figure B). The primary gross tumor volume of all scans was delineated by two investigators (SS and $\mathrm{BH}$ ), supervised and checked by HG. Nondiagnostic CT-scans, including non-contrast enhanced CT-scans and scans without a well delimited intrapulmonary primary tumor were excluded. Furthermore, some scans had to be excluded due to technical problems with feature extraction (mostly variable slice spacing). The dataset was divided in a training set (SCLC $(\mathrm{N}=48)$ and NSCLC $(\mathrm{N}=76)$ ) and external validation set (validation set 1 , SCLC $(\mathrm{N}=58)$ and NSCLC $(\mathrm{N}=40)$ ). The resulting signature was applied to the dataset of LCNEC cases (validation set 2, pSCLC-like $(\mathrm{N}=28)$ and pNSCLC-like $(\mathrm{N}=8)$ LCNEC) (Supplemental figure B). CT-image pre-processing, radiomics feature extraction, and feature harmonization are described extensively in Supplemental methods C.

\section{Results}

\subsection{Imaging interpretation}

The survey results of 23 pulmonary oncologists were used for analysis (Fig. 1A). In the control group, the 2 patients by consensus allocated as iSCLC-like, were indeed SCLC (PPV 100\%), and 7/8 patients allocated as iNSCLC-like were NSCLC (PPV 88\%). In the LCNEC group, 1/44 was classified as iSCLC-like and 19/34 were classified as iNSCLC-like. The only LCNEC allocated as iSCLC-like was also pSCLC-like (PPV 100\%). However, out of 19 patients regarded as iNSCLC-like, only 4 were pNSCLC-like, resulting in a PPV of $21 \%$ for an iNSCLC-like test being pNSCLC-like (Fig. 1A, Supplemental table A).

The radiologists also scored 2 SCLCs as iSCLC-like (PPV 100\%), while only 6/9 iNSCLC-like scored cases represented NSCLC (PPV 66\%). In the LCNEC group, 2/38 were allocated to the iSCLC-like group and 8/38 to the iNSCLC-like group. The PPV of an iSCLC-like scan to be a pSCLC-like LCNEC was $100 \%(2 / 2)$, but PPV of an iNSCLC-like scan to be pNSCLClike LCNEC was only $13 \%$ (1/8) (Fig. 1B, Supplemental table A).

\subsection{Semantic features}

An overview of all semantic features for 50 stage IV LCNEC is provided in Table 1 . A peripheral location was more common than a central location $(20 / 50(40 \%) v s .9 / 50(18 \%))$, while in 21 cases location was not determinable/no consensus ( $42 \%)$. In the control group, SCLC was more often located centrally compared to NSCLC (3/10 vs. 0/10, $\mathrm{p}=0.040$ ). No significant differences were observed in semantic features between 1) pSCLC-like and pNSCLC-like LCNEC and 2) other features of SCLC and NSCLC (Fig. 2, Supplemental table B).

\subsection{Radiomics signature}

A dataset of scans of SCLC and NSCLC patients was used to train a random forest model to separate both tumor types (Supplemental figure 


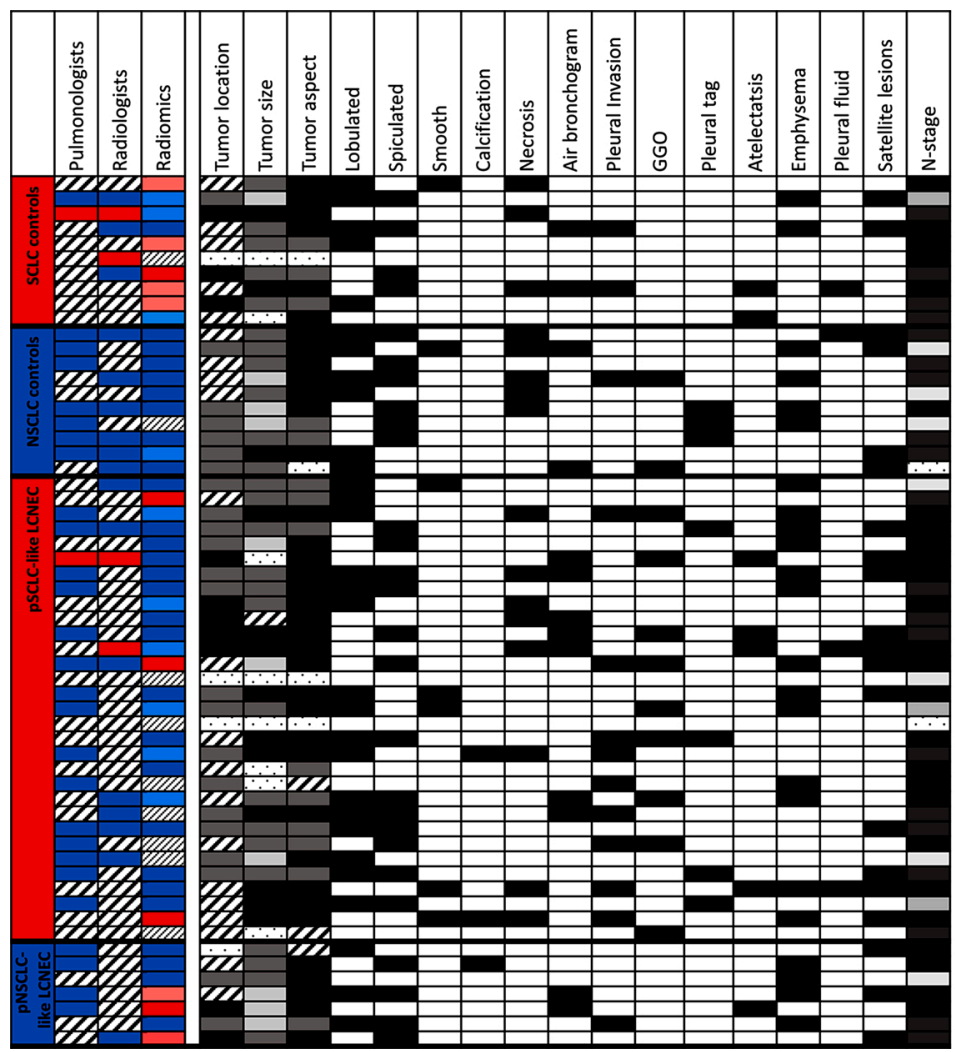

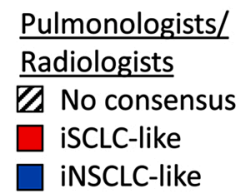

Radiomics probability*
囚 Not determined
$\square 0-0.200$
$\square 0.201-0.500$
$\square 0.501-0.800$
$\square 0.800-1$

Tumor location
$\square$ Not determinable
$\square$ No consensus
$\square$ Peripheral
Central
Tumor size
$\square$ Not determinable
$\square$ No consensus
$\square<3 \mathrm{~cm}$
3-7cm
$>7 \mathrm{~cm}$
Tumor aspect
$\square$ Not determinable
$\square$ No consensus
$\square$ Homogeneous
Heterogeneous
N-stage
$\square$ Not determinable
$\square$ No consensus
$\square$ N1
N2
N3
Other
$\square$ Negative
Positive

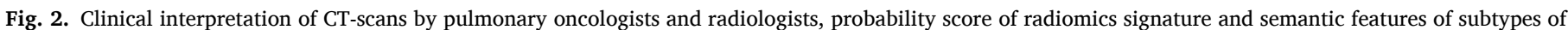

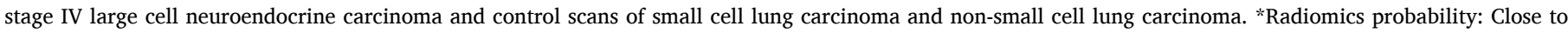

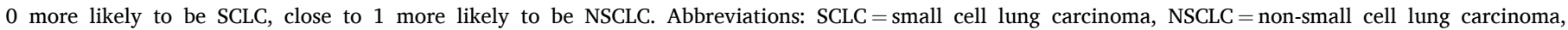

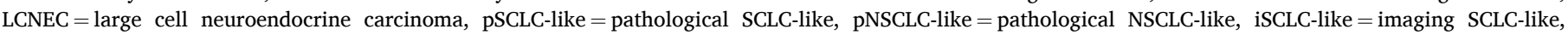
iNSCLC-like = imaging NSCLC-like, GGO = ground glass opacities, N-stage $=$ nodal stage

$\mathrm{B}$, Supplemental figure E). The area under the operating characteristics curve (AUC) for this model was 0.84 (95\% confidence interval (CI) 0.76 - 0.92) and for the external validation set of SCLC and NSCLC 0.84 (95\% CI 0.77-0.92). The validated model was applied to the scans of pSCLClike and pNSCLC-like LCNEC patients, which resulted in an AUC of 0.58 (95\% CI 0.29 - 0.86) (Supplemental figures F-H). According to the model 7/36 LCNEC were allocated to the SCLC category and 29/36 to the NSCLC category. In the subtypes, $4 / 28$ scans of pSCLC-like LCNEC were allocated to the SCLC category and 5/8 pNSCLC-like LCNEC were allocated to the NSCLC category (Fig. 2). The PPV of a SCLC category outcome of the model to be a pSCLC-like LCNEC was therefore $57 \%$. The PPV of a NSCLC category outcome of the model to be pNSCLC-like LCNEC was only $17 \%$.

\section{Discussion}

In this study, we have investigated whether pSCLC-like and pNSCLClike stage IV LCNEC could be distinguished on CT-scans based on imaging interpretation, semantic features or a radiomics signature. Pathological diagnosis of LCNEC is complicated and preferably, surgical resected tumor tissue is used [3]. However, patients with LCNEC often present with disseminated disease and the diagnosis is generally based on small tumor biopsies, that are not always conclusive regarding the histological subtype of the tumor, requiring larger and/or repeated biopsies [1]. Here, we tried to find less invasive alternatives to subclassify LCNEC. The radiomics signature trained on scans of SCLC and NSCLC patients was able to identify SCLC and NSCLC in an external validation set. However, pSCLC-like and pNSCLC-like LCNEC could not be separated by this signature. The subclassification between molecular LCNEC subtypes could neither be made based on imaging interpretation or semantic features. Moreover, LCNEC cases showed features of both SCLC and NSCLC, showing that LCNEC is a separate entity.

In this study, experienced pulmonary oncologists and chest radiologists could fairly differentiate between SCLC and NSCLC based features provided by CT-scans. However, no difference between pSCLC-like and pNSCLC-like LCNEC could be identified. So far, only one study of 8 LCNEC patients found 3/4 pSCLC-like LCNEC to be located central and 3/4 pNSCLC-like LCNEC to be located peripheral [10]. Based on the results of our study, in case the interpretation of a CT-scan of stage IV lung cancer by consensus is 'small cell-like', pathologic investigations will probably confirm SCLC morphology or pSCLC-like LCNEC. In contrast, if the interpretation is 'non-small cell-like', pathology can still reveal SCLC or PSCLC-like LCNEC, and no clinical consequences should be imposed.

Semantic features in a cohort of 50 stage IV LCNEC patients have not been investigated previously. The percentages of semantic features we found are in general comparable to those of smaller series including mainly stage I-III LCNEC (Table 2) [11-15,19]. Most semantic features in LCNEC were identified in percentages in between percentages previously described for SCLC and NSCLC. For example, the percentage of central LCNEC lesions was in between that of SCLC and NSCLC and similar patterns were seen for pleural tags, distal atelectases, liver metastases and $\mathrm{N}$-stage $[11,12,14,18]$. This indicates that LCNEC is a unique disease with characteristics of both SCLC and NSCLC.

We created an accurate radiomics signature that was able to classify SCLC and NSCLC based on CT-scans. To the best of our knowledge, only two studies, both without external validation, have reported on the separation of SCLC and NSCLC, constructing signatures with an AUC of 0.74 (95\% CI 0.68-0.80) and $>0.60$, respectively $[8,9]$. Despite the good performance of our signature in the SCLC $v s$. NSCLC external validation 
set, our model was unable to separate pSCLC-like and pNSCLC-like LCNEC. This indicates that pSCLC-like LCNEC and SCLC as well as pNSCLC-like LCNEC and NSCLC have different quantitative imaging features. This further adds to the unique characteristics of LCNEC compared to both SCLC and NSCLC.

This study has several limitations. First, a limited number of CT-scans of stage IV LCNEC patients was available for this study due to the rarity of LCNEC and various technical and regulatory bottlenecks to obtain scans from multiple hospitals. Furthermore, development of the radiomics model was complicated by quite high heterogeneity in the applied scanning protocol, probably due to the long time frame in which the examinations were performed (2003-2018) and the large number of hospitals included from all over the Netherlands. To correct for interscanner model, acquisition protocol and reconstruction settings variation, we used the ComBat statistical harmonization technique available for multicenter imaging studies before developing the radiomics signature [20-22].

In conclusion, LCNEC has radiological characteristics of both SCLC and NSCLC, but these characteristics do not correlate with pSCLC-like and pNSCLC-like LCNEC subtypes based on imaging interpretation by pulmonary oncologists and radiologists, semantic features or a radiomics signature designed to differentiate between SCLC and NSCLC. Most LCNEC were classified by clinicians and radiomics as NSCLC-like despite SCLC-like molecular characteristics, highlighting LCNEC as a unique tumor entity.

\section{Declaration of Competing Interest}

Drs. Hermans reports grants from Bristol-Myers Squibb, nonfinancial support from Abbvie, outside the submitted work;

Dr. Derks reports grants from Bristol-Myers Squibb, non-financial support from Abbvie, outside the submitted work;

personal fees from BMS, personal fees from Pfizer, personal fees from Boehringer-Ingelheim, personal fees from Novartis, personal fees from Ipsen, outside the submitted work;

Dr. Woodruff reports grants from KWF, during the conduct of the study; and Dr Woodruff has (minority) shares in the company Oncoradiomics.

Dr. Speel reports grants from Bristol-Myers Squibb, Astra Zeneca, Pfizer, Novartis and MSD, personal fees from AbbVie and Roche, nonfinancial support from Abbvie, outside the submitted work;

Dr. Lambin reports grants from ERC advanced grant (ERC-ADG2015, n 694812 - Hypoximmuno, grants from EUROSTARS, grants from ITN - PREDICT, grants from TRANSCAN JointTransnational Call 2016 (JTC2016 "CLEARLY"-, grants from Interreg V-A Euregio Meuse-Rhine ("Euradiomics"), personal fees from Oncoradiomics, grants from European commission, during the conduct of the study; other from Varian medical, other from Elekta, other from ptTheragnostic, outside the submitted work; In addition, Dr. Lambin has a patent PCT/NL2014/ 050248 licensed to Oncoradiomics, a patent PCT/NL2014/050728 licensed to Oncoradiomics, and patents N2024482, N2024889, N2024889 pending and Dr Lambin has minority shares in the company Oncoradiomics SA.

\section{Funding sources}

This research did not receive any specific grant from funding agencies in the public, commercial, or not-for-profit sectors.

\section{CRediT authorship contribution statement}

B.C.M. Hermans: Conceptualization, Methodology, Formal analysis, Investigation, Writing - original draft, Visualization. S. Sanduleanu: Methodology, Software, Formal analysis, Investigation, Writing original draft, Visualization. J.L. Derks: Conceptualization, Methodology, Writing - review \& editing. H. Woodruff: Software, Methodology, 
Writing - review \& editing. L.M. Hillen: Investigation, Writing - review \& editing. R. Casale: Investigation, Writing - review \& editing. F. Mohamed Hoesein: Investigation, Writing - review \& editing. E. de Jong: Resources, Data curation, Writing - review \& editing. D.M.H.J. ten Berge: Resources, Data curation, Writing - review \& editing. E.J.M. Speel: Conceptualization, Writing - review \& editing. P. Lambin: Methodology, Software, Writing - review \& editing. H.A. Gietema: Conceptualization, Methodology, Investigation, Writing - review \& editing. A-M.C. Dingemans: Conceptualization, Methodology, Writing review \& editing, Supervision.

\section{Declaration of Competing Interest}

Dr. Dingemans reports grants from Bristol-Myers Squibb, personal fees from Roche, BMS, Eli Lily, Takeda and Boehringer Ingelheim, nonfinancial support from Abbvie, outside the submitted work; The other authors did not report conflicts of interest.

\section{Acknowledgement}

We thank E. van den Broek and colleagues from PALGA for selection of LCNEC patients from the PALGA database and providing pathological material. We thank all pulmonologists who provided CT-scans of LCNEC patients. We would also like to thank the pulmonary oncologists who participated in this study by filling out the survey on imaging interpretation.

\section{Appendix A. Supplementary data}

Supplementary material related to this article can be found, in the online version, at doi:https://doi.org/10.1016/j.lungcan.2020.08.006.

\section{References}

[1] J.L. Derks, L.E. Hendriks, W.A. Buikhuisen, H.J. Groen, E. Thunnissen, R.J. van Suylen, R. Houben, R.A. Damhuis, E.J. Speel, A.M. Dingemans, Clinical features of large cell neuroendocrine carcinoma: a population-based overview, Eur Respir J 47 (2) (2016) 615-624.

[2] H. Takei, H. Asamura, A. Maeshima, K. Suzuki, H. Kondo, T. Niki, T. Yamada, R. Tsuchiya, Y. Matsuno, Large cell neuroendocrine carcinoma of the lung: a clinicopathologic study of eighty-seven cases, J Thorac Cardiovasc Surg 124 (2) (2002) 285-292.

[3] W.D. Travis, E. Brambilla, A.P. Burke, A. Markx, A.G. Nicholson, WHO Classification of Tumours of the Lung, Pleura, Thymus and Heart, Fourth ed., International Agency for Research on Cancer, Lyon, France, 2015.

[4] N. Rekhtman, M.C. Pietanza, M.D. Hellmann, J. Naidoo, A. Arora, H. Won, D. F. Halpenny, H. Wang, S.K. Tian, A.M. Litvak, P.K. Paik, A.E. Drilon, N. Socci, J. T. Poirier, R. Shen, M.F. Berger, A.L. Moreira, W.D. Travis, C.M. Rudin, M. Ladanyi, Next-Generation Sequencing of Pulmonary Large Cell Neuroendocrine Carcinoma Reveals Small Cell Carcinoma-like and Non-Small Cell Carcinoma-like Subsets, Clin Cancer Res 22 (14) (2016) 3618-3629.

[5] J. George, V. Walter, M. Peifer, L.B. Alexandrov, D. Seidel, F. Leenders, L. Maas, C. Muller, I. Dahmen, T.M. Delhomme, M. Ardin, N. Leblay, G. Byrnes, R. Sun, A. De Reynies, A. McLeer-Florin, G. Bosco, F. Malchers, R. Menon, J. Altmuller, C. Becker, P. Nurnberg, V. Achter, U. Lang, P.M. Schneider, M. Bogus, M. G. Soloway, M.D. Wilkerson, Y. Cun, J.D. McKay, D. Moro-Sibilot, C.G. Brambilla, S. Lantuejoul, N. Lemaitre, A. Soltermann, W. Weder, V. Tischler, O.T. Brustugun, M. Lund-Iversen, A. Helland, S. Solberg, S. Ansen, G. Wright, B. Solomon, L. Roz, U. Pastorino, I. Petersen, J.H. Clement, J. Sanger, J. Wolf, M. Vingron, T. Zander, S. Perner, W.D. Travis, S.A. Haas, M. Olivier, M. Foll, R. Buttner, D.N. Hayes,
E. Brambilla, L. Fernandez-Cuesta, R.K. Thomas, Integrative genomic profiling of large-cell neuroendocrine carcinomas reveals distinct subtypes of high-grade neuroendocrine lung tumors, Nat Commun 9 (1) (2018) 1048.

[6] J.L. Derks, N. Leblay, E. Thunnissen, R.J. van Suylen, M. den Bakker, H.J.M. Groen, E.F. Smit, R. Damhuis, E.C. van den Broek, A. Charbrier, M. Foll, J.D. McKay, L. Fernandez-Cuesta, E.M. Speel, A.C. Dingemans, P. Group, Molecular Subtypes of Pulmonary Large-cell Neuroendocrine Carcinoma Predict Chemotherapy Treatment Outcome, Clin Cancer Res 24 (1) (2018) 33-42.

[7] M. Zhuo, Y. Guan, X. Yang, L. Hong, Y. Wang, Z. Li, R. Chen, H.A. Abbas, L. Chang, Y. Gong, N. Wu, J. Zhong, W. Chen, H. Chen, Z. Dong, X. Zhu, J. Li, Y. Wang, T. An, M. Wu, Z. Wang, J. Wang, E.B. Roarty, W. Rinsurongkawong, J. Lewis, J.A. Roth, S. G. Swisher, J.J. Lee, J.V. Heymach, I.I. Wistuba, N. Kalhor, L. Yang, X. Yi, P. A. Futreal, B.S. Glisson, X. Xia, J. Zhang, J. Zhao, The Prognostic and Therapeutic Role of Genomic Subtyping by Sequencing Tumor or Cell-Free DNA in Pulmonary Large-Cell Neuroendocrine Carcinoma, Clin Cancer Res 26 (4) (2020) 892-901.

[8] L. E, L. Lu, L. Li, H. Yang, L.H. Schwartz, B. Zhao, Radiomics for Classification of Lung Cancer Histological Subtypes Based on Nonenhanced Computed Tomography, Acad Radiol (2018).

[9] L. E, L. Lu, L. Li, H. Yang, L.H. Schwartz, B. Zhao, Radiomics for Classifying Histological Subtypes of Lung Cancer Based on Multiphasic Contrast-Enhanced Computed Tomography, J Comput Assist Tomogr 43 (2) (2019) 300-306.

[10] F. Zhou, L. Hou, T. Ding, Q. Song, X. Chen, C. Su, W. Li, G. Gao, S. Ren, F. Wu, J. Fan, C. Wu, J. Zhang, C. Zhou, Distinct clinicopathologic features, genomic characteristics and survival of central and peripheral pulmonary large cell neuroendocrine carcinoma: From different origin cells? Lung Cancer 116 (2018) 30-37.

[11] K.J. Jung, K.S. Lee, J. Han, O.J. Kwon, J. Kim, Y.M. Shim, T.S. Kim, Large cell neuroendocrine carcinoma of the lung: clinical, CT, and pathologic findings in 11 patients, J Thorac Imaging 16 (3) (2001) 156-162.

[12] S. Akata, S. Okada, J. Maeda, J. Park, M. Yoshimura, K. Saito, D. Kakizaki, K. Abe, $\mathrm{H}$. Kato, Computed tomographic findings of large cell neuroendocrine carcinoma of the lung, Clin Imaging 31 (6) (2007) 379-384.

[13] A.R. Shin, B.K. Shin, J.A. Choi, Y.W. Oh, H.K. Kim, E.Y. Kang, Large cell neuroendocrine carcinoma of the lung: radiologic and pathologic findings, J Comput Assist Tomogr 24 (4) (2000) 567-573.

[14] K.W. Lee, Y. Lee, S.W. Oh, K.N. Jin, J.M. Goo, Large cell neuroendocrine carcinoma of the lung: CT and FDG PET findings, Eur J Radiol 84 (11) (2015) 2332-2338.

[15] Y. Oshiro, M. Kusumoto, Y. Matsuno, H. Asamura, R. Tsuchiya, H. Terasaki, H. Takei, A. Maeshima, S. Murayama, N. Moriyama, CT findings of surgically resected large cell neuroendocrine carcinoma of the lung in 38 patients, AJR Am J Roentgenol 182 (1) (2004) 87-91.

[16] P. Lambin, R.T.H. Leijenaar, T.M. Deist, J. Peerlings, E.E.C. de Jong, J. van Timmeren, S. Sanduleanu, R. Larue, A.J.G. Even, A. Jochems, Y. van Wijk, H. Woodruff, J. van Soest, T. Lustberg, E. Roelofs, W. van Elmpt, A. Dekker, F. M. Mottaghy, J.E. Wildberger, S. Walsh, Radiomics: the bridge between medical imaging and personalized medicine, Nat Rev Clin Oncol 14 (12) (2017) 749-762.

[17] P. Lambin, E. Rios-Velazquez, R. Leijenaar, S. Carvalho, R.G. van Stiphout, P. Granton, C.M. Zegers, R. Gillies, R. Boellard, A. Dekker, H.J. Aerts, Radiomics: extracting more information from medical images using advanced feature analysis, European journal of cancer (Oxford, England : 1990) 48 (4) (2012) 441-446.

[18] S. Rizzo, S. Raimondi, E.E.C. de Jong, W. van Elmpt, F. De Piano, F. Petrella, V. Bagnardi, A. Jochems, M. Bellomi, A.M. Dingemans, P. Lambin, Genomics of non-small cell lung cancer (NSCLC): Association between CT-based imaging features and EGFR and K-RAS mutations in 122 patients-An external validation, Eur J Radiol 110 (2019) 148-155.

[19] K. Takamochi, T. Yokose, J. Yoshida, M. Nishimura, H. Ohmatsu, K. Nagai, Y. Nishiwaki, A. Ochiai, Calcification in large cell neuroendocrine carcinoma of the lung, Jpn J Clin Oncol 33 (1) (2003) 10-13.

[20] W.E. Johnson, C. Li, A. Rabinovic, Adjusting batch effects in microarray expression data using empirical Bayes methods, Biostatistics (Oxford, England) 8 (1) (2007) 118-127.

[21] F. Lucia, D. Visvikis, M. Vallieres, M.C. Desseroit, O. Miranda, P. Robin, P. A. Bonaffini, J. Alfieri, I. Masson, A. Mervoyer, C. Reinhold, O. Pradier, M. Hatt, U. Schick, External validation of a combined PET and MRI radiomics model for prediction of recurrence in cervical cancer patients treated with chemoradiotherapy, European journal of nuclear medicine and molecular imaging 46 (4) (2019) 864-877.

[22] F. Orlhac, F. Frouin, C. Nioche, N. Ayache, I. Buvat, Validation of A Method to Compensate Multicenter Effects Affecting CT Radiomics, Radiology 291 (1) (2019) 53-59. 